disturbance must have been considerable. At St. Mary Cray, there is no evidence of occupation, at least since Roman times. It is possible, therefore, that they may serve the needs of the archæologist to better effect, and it may be, throw further light on the prehistoric excavators of the chalk, to whose activities the dene holes, notably near Croydon, bear witness. Exploration of the newly discovered caves will begin as soon as the subsided clay has been removed and the roof of one of the chambers has been supplied with the necessary shoring.

\section{Modern Developments in Broadcasting}

IN a paper read before the Institution of Civil Engineers on February 16, Sir Noel Ashbridge traced briefly the growth of broadcasting transmission and television, and referred to some of the recent developments arising from the researches carried out by the B.B.C. The paper dealt at some length with the design of studios and the effect of size, shape and materials upon their acoustic properties. The advantages of the ribbon microphone over its predecessors were referred to, and the principal methods of sound recording were described. Improvements in the design of transmitting stations are broadly covered by schemes for economizing the power required for producing a given radiation output, and by the use of high vertical aerials, which tend to concentrate the radiation in the horizontal plane so as to give the most efficient service area. Sir Noel remarked on the difficulty of accommodating all the European broadcasting stations within the available wave-length band, and described the expedient of sharing wave-lengths between two or more transmitting stations by synchronizing their carrier waves. Next, a reference was made to the Empire broadcasting service, and the reasons which necessitated the use of short waves for this purpose were outlined. As a result of research carried out on the design of short-wave aerials to give the most efficient radiation, a considerable improvement is to be expected in overseas reception when the new short-wave transmitters of the B.B.C. are brought into operation in the near future. The paper concluded with a brief description of the methods and technique being employed for the transmissions from the London Television Station on ultra-short waves. The results of field strength surveys round London were given, and reference was made to the effect of interference from motor-cars and electrical apparatus.

\section{Ultra-Short Wave Broadcasting}

THE broadcasting service from the Alexandra Palace television station has already illustrated the suitability of ultra-short waves as a medium for the transmission not only of high-definition pictures but also of speech and music of very high quality. The latter achievement arises from the fact that in the ultra-short wave-band, the permissible band width available for the modulation frequencies is many times that obtainable amidst the present congested conditions in the medium and long-wave broadcasting bands. It is rather natural to suggest, therefore, that more use might be made of the ultra-short wavelengths for high-fidelity sound broadcasting. This matter was referred to in a note in The Times of February 18, in which it was pointed out that this aspect has been under consideration by the B.B.C. for some time past. Indeed, experiments were carried out some years ago with a transmitter installed on the roof of Broadcasting House and operated on a wave-length of six metres. Further experiments are being conducted, but it is stated that no plans have yet been made for the development of a public service on these lines. A large-scale extension of the ultra-short wave broadcasting of sound would be complicated by at least two factors. First is the fact that the B.B.C. is not the only user of the band of wave-lengths below ten metres, for some other national services already have vested interests there. Secondly, there is the difficult problem of interference from the ignition systems of motor-cars, which cause very unpleasant noises in neighbouring receivers working on ultra-short waves. It would seem to be unlikely that broadcasting on these wavelengths will become really popular until the fitting of suppression devices to such ignition systems is made compulsory.

\section{Radio-Elements as Research Tools}

IN a lecture to the Society of Chemical Industry on March 1, Prof. F. A. Paneth discussed "RadioElements in Chemical and Biological Research". Owing to the extreme sensitivity of electrometric methods it is possible to detect radio-elements in much smaller concentrations than any other chemical substances; and as they are isotopic with ordinary elements we can in many investigations substitute a radio-element for its inactive isotope. Such use of 'radio-elements' as indicators is frequently of great help if the behaviour of an element in very small concentration has to be investigated. Perhaps of even greater importance is a slightly different application. By mixing a fraction of a stable element with its radioactive isotope we can differentiate this fraction from the rest of the element, and then study the exchange of atoms of identical chemical properties. It is especially this use of 'indicated atoms' which opens the door to otherwise insoluble problems. Since the discovery of artificial radio-elements, almost every chemical element can be obtained in the form of its radioactive isotope, and the use of radio. elements as indicators has been greatly extended.

Among the problems to the solution of which radioelements have contributed are the determination of the solubility of very slightly soluble compounds, the preparation of the volatile hydride of bismuth, the study of the permeability to air of almost completely airtight gas-mask fabrics, of the formation of alloys at low temperatures, the rate of solution of exceedingly thin films, and electro-deposition from extremely dilute solutions. With the help of 'indicated atoms' the diffusion of lead into lead, the determination of the surface of adsorbing crystalline powders, the exchange of atoms of one and the same kind in 
chemical reactions have been studied for the first time. The active isotopes of carbon, phosphorus, sodium, calcium and other elements of special importance in biology make it possible to investigate the metabolism of these atoms. The use of radioelements as indicators is steadily increasing and it is to be expected that in future many chemical, physical and biological laboratories will avail themselves of the great possibilities offered by this method in the study of an infinite variety of problems.

\section{Bird Preservation}

THE British Section of the International Committee for Bird Preservation, of which Dr. Percy Lowe is chairman and Mr. D. Seth-Smith treasurer, is appealing for support. It is governed by a committee of sixteen drawn from the Royal Society, the Royal Society of Edinburgh, the Zoological Society of London, the British Ornithologists' Union, the Royal Society for the Protection of Birds, the National Trust, the Society for the Promotion of Nature Reserves and the Society for the Preservation of the Fauna of the Empire. The British Section is not only representative of bird protection interests in Great Britain but, in addition, is in direct communication with similar sections of twenty-six nations. Its work is essentially international in character and deals with problems which can only be solved by scientific and even 'political' work on a very wide front. These include the drafting of a new international convention for the protection of European birds ; the destruction of birds by waste oil at sea ; the protection of the quail, which is caught in thousands during the breeding season for export to European countries; the conditions under which live birds are transported by sea; and an inquiry into the status of the Anatidæ. This latter, which is regarded as vitally important by scientific workers and sportsmen throughout Europe, includes investigations ranging from the conditions obtaining in northern breeding grounds to the diminution of Zostera marina. Of paramount importance is a scheme for ringing duck in order to trace their lines of migration. To carry out this work adequately it is essential that the income of the British Section should be greatly increased. All persons interested are therefore invited to become either patrons at three guineas or associates at $10 s$. 6d. a year. Subscriptions should be sent to the Secretary, Miss Phyllis Barclay-Smith, British Section, I.C.B.P., c/o Zoological Society of London, Regent's Park, N.W.8.

\section{Town Planning and Decentralization}

THE relationship of man to his work and his environment was explored from various aspects at a conference held by the Garden Cities and Town Planning Association, at the Housing Centre, 13 Suffolk Street, S.W.1, on February 27. Dr. Norman MacFayden, former medical officer of health for Letchworth, showed statistically that the satellite town has proved its great value from the health point of view; his comparative figures for tuberculosis and pneumonia were particularly convincing.
He stressed the close relationship between man and Nature which is taken into account in the planning of garden cities, but which the modern congested cities, for example, London, Manchester, Glasgow, cannot provide. The case for the satellite town was further strengthened by papers presented by G. L. Pepler, Colin Clarke and Dr. D. H. Smith. Dr. Smith gave a full account of the uncontrolled location of industries in the Lea Valley on the outskirts of London, and pointed out that in the great majority of cases there was no reason why the factories should not have been located at a greater distance, within satellite towns. He listed a number of problems : noise, traffic congestion, traffic control, vulnerability in war time, journeys to work, as well as health and æsthetic aspects which should be further investigated and could be solved by decentralization. Mr. Colin Clarke estimated the change in the proportion of workers employed in manufacturing industries for 'export' and as compared with local industries and services, and concluded that the increase in the latter, following upon an increased standard of living, will also favour decentralization during the coming decades.

\section{Electricity Supply in Great Britain}

ON March 3, in reply to a question by Sir M. Macdonald, Mr. Hore-Belisha, the Minister of Trans. port, said that his Majesty's Government has decided to adopt in principle the recommendations of the MeGowan Committee for a reorganization of electricity supply of the country. A few minor modifications would be added, which he understood would be generally acceptable. In the report it is stated that any attempt to carry through a scheme of reorganization on a voluntary basis would fail, and legislation must confer definite and adequate compulsory powers. It is also stated that schemes of reorganization should make provision for the possibility of ultimate public ownership of all undertakings, including those not at present subject to purchase by the local authorities. Complete standardization of systems and voltages and of methods of charge, as well as amalgamation of a large number of small undertakings into a smaller number of large ones will be necessary. As a result of such reorganization, considerable further development of rural areas should be possible. The scheme recommended by the McGowan Committee should result in a general, though necessarily gradual, reduction in costs. It rejects nationalization as a solution of the distribution problem, at least in the present stage of the evolution of the industry. It prefers to proceed by the gradual method of overhaul and consolidation and a more efficient grouping of existing undertakings. In a report published last December by PEP (Political and Economic Planning, 16 Queen Anne's Gate, S.W.1), the problem is summed up by saying that the public expects that the supply industry will hasten towards a future where the residential consumer, the farmer and the industrialist will have full freedom to use electricity to the greatest advantage. This will obviously take several years. 